\title{
A full conformational characterization of antiandrogen cortexolone-17 $\alpha$-propionate and related compounds through theoretical calculations and nuclear magnetic resonance spectroscopy
}

Cite this: Med. Chem. Commun., 2014, 5,904

\author{
Patrizia Ferraboschi, ${ }^{a}$ Laura Legnani, ${ }^{\text {ab }}$ Giuseppe Celasco, ${ }^{c}$ Luigi Moro, ${ }^{c}$ \\ Laura Ragonesi ${ }^{c}$ and Diego Colombo*a
}

Cortexolone-17 $\alpha$-propionate is a topical antiandrogen under investigation for the treatment of androgenrelated skin disorders. A full conformational characterization was realized, in comparison with other steroidal androgens and antiandrogens, by means of theoretical calculations at the B3LYP/6-31G(d) level supported by high-field NMR analyses. All of the studied molecules showed a good overlay; nevertheless, the different functional groups present in the skeleton of the molecules drive the individual

biological profile.

Received 7th February 2014

Accepted 4th April 2014

DOI: $10.1039 / c 4 m d 00049 h$

www.rsc.org/medchemcomm

\section{Introduction}

The skin's capability of synthesizing and converting androgens is well documented. ${ }^{1}$ The $5 \alpha$-reductase-catalyzed transformation of testosterone 1 affords dihydrotestosterone (DHT,

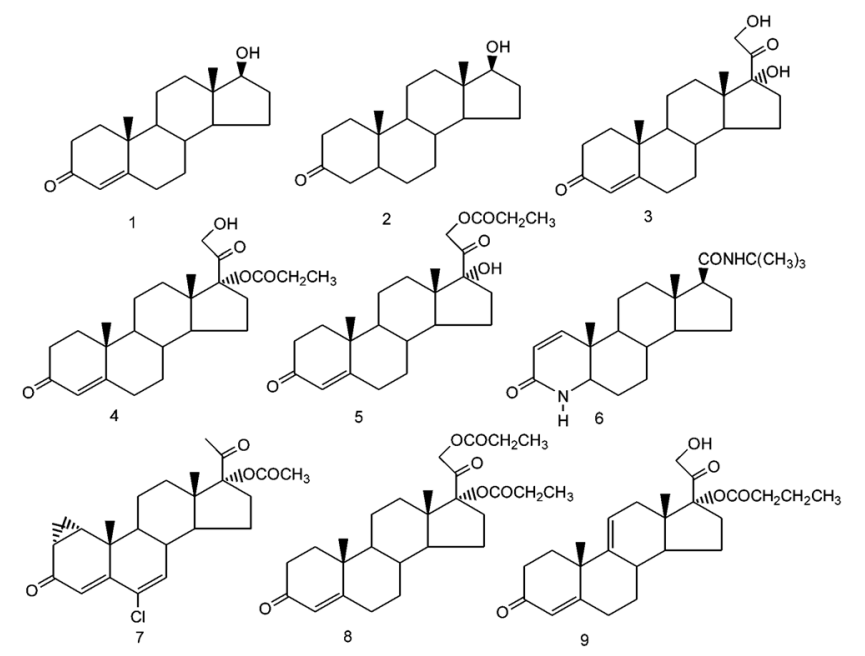

Fig. 1 Structures of the studied compounds.

${ }^{a}$ Dipartimento di Biotecnologie Mediche e Medicina Traslazionale, Università di Milano, Via Saldini 50, 20133 Milano, Italy. E-mail: diego.colombo@unimi.it; Fax: +39-0250316036; Tel: +39-0250316039

${ }^{b}$ Dipartimento di Chimica - Università degli Studi di Pavia, Via Taramelli 12, 27100 Pavia, Italy

${ }^{c}$ Cosmo Research \& Development S.p.A., Via C. Colombo 1, 20020 Lainate, MI, Italy
2) (Fig. 1), the most active metabolite involved in many androgen-related skin disorders such as hirsutism, androgen alopecia and acne. ${ }^{1-5}$ The treatment of these disorders can be realized by either inhibiting the $5 \alpha$-reductase or antagonizing the binding of testosterone and DHT at the androgen binding sites. ${ }^{6}$ Known androgen antagonists, such as finasteride 6 or cyproterone acetate 7 , when systemically administered, show beneficial effects in the management of these skin disorders together with an interference with the hormonal environment in male and female patients. ${ }^{7}$ Several years ago we investigated ${ }^{8}$ the antiandrogenic activity of a family of $17 \alpha$-esters of cortexolone (17 2,21 -dihydroxy-4-pregnene-3,20-dione 3), an intermediate of the glucocorticoid biosynthesis, devoid of endocrine function, with the exception of a weak glucocorticoid activity. ${ }^{9}$ Among the studied esters, $17 \alpha$-propionate 4 showed a strong local antiandrogenic activity in the hamster flank organ test $\mathrm{t}^{10}$ being, on the contrary, ineffective when subcutaneously injected by repeated administrations in animals even at very high doses. ${ }^{8}$ The systemic antiandrogenic activity of $17 \alpha$-propionate of cortexolone was assessed by its ability to decrease the weight of the androgen-dependent organs (ventral prostate, seminal vesicles and preputial glands) stimulated by the injection of testosterone propionate (TP). ${ }^{8}$

The absence of systemic antiandrogenic effects could be explained considering that the propionate, after percutaneous application, is quickly hydrolyzed by the skin and plasma esterases into the inactive parent cortexolone (3) getting through the 21-propionate 5.

The topical activity of compound $\mathbf{4}$ is higher than that of finasteride 6 and about equivalent to that of cyproterone acetate 7 . 
Taking into account the topical activity of propionate 4 coupled with the lack of systemic activity, we planned to compare this $17 \alpha$-ester with the well-known antiandrogen cyproterone acetate 7 and with the natural androgens, testosterone $\mathbf{1}$ and dihydrotestosterone $\mathbf{2}$, from a conformational point of view.

In fact, the conformation of a biologically active compound plays a central role when it interacts with the target, for example, a receptor or an enzyme; among the possible conformations only one could be able to stimulate the biological response as we also reported in a previous work. ${ }^{\mathbf{1 1}}$ The choice of the compounds to be compared with propionate 4 was driven by its antiandrogenic activity. In fact testosterone (1) and dihydrotestosterone (2) are antagonized both by compounds 4 and 7 with the same action mechanism that does not implicate the interference with the $5 \alpha$-reductase. The conformational characterization was realized by means of theoretical calculations, validated by complete assignment of the ${ }^{1} \mathrm{H}$ and ${ }^{13} \mathrm{C}$ NMR signals, as in the case of our previous studies of steroidal compounds. ${ }^{11}$

\section{Results and discussion}

\section{Biological activity of cortexolone-17 $\alpha$-propionate (4)}

Local activity and mechanism of action of cortexolone-17 $\alpha$ propionate (4). The local activity of $\mathbf{4}$ was established by means of the hamster flank organ test. ${ }^{8}$ The results are summarized in Table 1 (for a more exhaustive discussion see ref. 8). The antiandrogenic activity of $\mathbf{4}$ is dose-related; the parent cortexolone (3) is devoid of effect; when compared to other androgen antagonists, administered at a fixed dose (400 $\mu \mathrm{g})$, compound 4 resulted in being two times more active than finasteride (6) and about as active as cyproterone acetate (7).

As concerns the mechanism of action, compound 4, compared to finasteride (6) the well-known inhibitor of $5 \alpha$ reductase, did not inhibit the conversion of testosterone (1) to DHT (2) in reconstructed human epidermis (Cosmo R \& D personal communication), thus resulting in the absence of inhibitory activity on the $5 \alpha$-reductase, as shown by the studied $\left[{ }^{14} \mathrm{C}\right]$-testosterone metabolism after $24 \mathrm{~h}$ transepidermal diffusion (Fig. 2).

Additional experiments (Cosmo R \& D personal communication) showed that in the binding affinity test to the androgen- receptor of human prostate cancer cells, compound 4 inhibited the specific binding of $\left[{ }^{3} \mathrm{H}\right]$ methyltrienolone (R1881) to the androgen receptor with a $K_{\mathrm{i}}$ value of $4.0 \times 10^{-8}$, and an $\mathrm{IC}_{50}$ value of $5.0 \times 10^{-8} \mathrm{M}$. As a consequence, compound 4 should be considered as an antiandrogen acting at the androgenreceptor level.

Systemic activity of cortexolone-17 $\alpha$-propionate (4). Systemic antiandrogenic activity of $\mathbf{4}$ was evaluated in male castrated rats primed with TP. After repeated subcutaneous injections of 0.2-1 and $5 \mathrm{mg}$ per animal, compound 4 was completely unable to antagonize the stimulating effect of TP on the target organs ventral prostate, seminal vesicles, and preputial glands. ${ }^{8}$ Also, parent cortexolone (3) resulted in being devoid of activity in this test. $^{8}$ Compound $\mathbf{4}$ was also endowed with glucocorticoid activity (adrenals and thymus weight inhibition), detectable only at the highest tested dose equivalent to about $100 \mathrm{mg}$ per $\mathrm{kg}$ of body weight. Considering the very high dose required to obtain the glucocorticoid activity, this effect should be minimal and of little importance when the product is administered by topical route. ${ }^{8}$ In addition, in the antigonadotropic activity test $17 \alpha$-propionate 4 , even injected at the highest dose, was completely devoid of activity on gonadotropin hypersecretion, as compared to progesterone. These data demonstrate that compound $\mathbf{4}$ is a peripherally selective antiandrogen not affecting the CNS. ${ }^{8}$

Metabolism of cortexolone-17 $\alpha$-propionate (4). The absence of systemic activity can be explained by a rapid hydrolysis of the $17 \alpha$-ester affording the inactive cortexolone (3). Cortexolone$17 \alpha$-propionate $(4)$, when incubated in rat plasma, was rapidly converted (50\%) to free cortexolone (3) within $2 \mathrm{~h}$ of incubation and completely metabolized within $8 \mathrm{~h}$ (Table 2). The acyl group

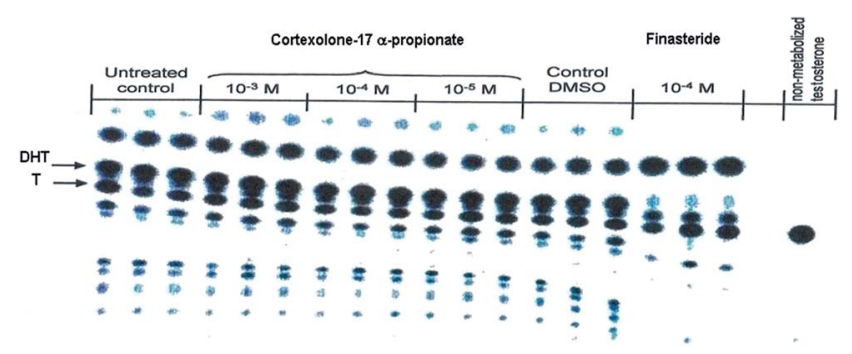

Fig. $2\left[{ }^{14} \mathrm{C}\right]$-testosterone $(\mathrm{T}, 1)$ metabolism and $\mathrm{DHT}(2)$ production in presence of cortexolone-17 $\alpha$-propionate (4) or finasteride (6).

Table 1 Local antiandrogenic activity in hamster flank organ ${ }^{a}$

\begin{tabular}{lll}
\hline Topical treatment (acetone $0.05 \mathrm{~mL})$ & Daily dose $^{b}$ & Flank organ inhibition $^{c}(\%)$ \\
\hline Cortexolone (3) + TP & $400+4$ & 0 \\
Finasteride (6) + TP & $400+4$ & $71^{*}$ \\
Cyproterone acetate (7) + TP & $400+4$ & $93^{* *}$ \\
Cortexolone-17 $\alpha$-propionate (4) + TP & $100+4$ & $40^{*}$ \\
Cortexolone-17 $\alpha$-propionate (4) + TP & $200+4$ & $78^{*}$ \\
Cortexolone-17 $\alpha$-propionate (4) + TP & $400+4$ & $84^{* *}$
\end{tabular}

${ }^{a}$ The local antiandrogenic activity of $\mathbf{4}$ and other tested compounds 3, 6, and 7 was expressed as the percentage inhibition of the flank organ enlargement induced by the topical application of testosterone propionate (TP) alone. ${ }^{b} \mu \mathrm{g}$ per animal, antiandrogen + androgen. ${ }^{c} * P<0.05$, $* * P<0.01$. 
initially undergoes a non-enzymatic migration to the 21-position and subsequently an esterase-catalyzed hydrolysis affording the inactive cortexolone (3). The formation of intermediate 5 was investigated by incubating 4 at $37.8^{\circ} \mathrm{C}$ for up to $8 \mathrm{~h}$ in the absence or presence of $50 \mu \mathrm{g} \mathrm{mL}^{-1}$ of enzymatic inhibitor dichlorvos. When the incubation was performed in the presence of the inhibitor, a large amount of cortexolone-21-propionate (5) was detected, thus confirming that the biotransformation of $17 \alpha$-propionate 4 to cortexolone (3) takes place by the production of 21-propionate 5 , as an effect of non-enzymatic migration of the propionyl group from the $17 \alpha$-position to the 21-position, and subsequent hydrolysis of the 21-propionate (5) to cortexolone (3).

An analogous metabolic profile of 4 was observed with incubation in human plasma (Table 3).

In rat skin homogenate the metabolic transformation of 4 to cortexolone (3) reached a peak (40-44.7\%) within 8-16 h, and remained stable during the remnant incubation period of up to $24 \mathrm{~h}$ (Table 4).

Biological activity of cortexolone-21-propionate (5) and cortexolone-17 $\alpha, 21$-dipropionate (8). In Table 5 is reported the local antiandrogenic activity of compounds $\mathbf{5}$ and 8, showing in the ability of the tested steroids $(400 \mu \mathrm{g})$ to inhibit the enlargement of the hamster flank organ test, in turn produced by the administration of TP $(4 \mu \mathrm{g})$. The 21-monoesterification of cortexolone (3) leads to compound 5 being nearly devoid of activity, like the parent cortexolone (3). The 17 $\alpha, 21$-diesterification (compound 8) reduces the antiandrogenic activity granted by the $17 \alpha$-esterification of compound 4 (84\% inhibition, Table 1).

Biological activity of 9,11-dehydrocortexolone-17 $\alpha$-butyrate (9). The 9,11-dehydrocortexolone-17 $\alpha$-butyrate (9), based on the results of the screening phase, was identified as the most potent topical antiandrogen among the $17 \alpha$-monoesters; in fact, it showed an $85 \%$ ability to inhibit the enlargement of the hamster's flank organ produced by topical administration of TP (Table 5), whereas the corresponding saturated $17 \alpha$-butyrate showed a $76 \%$ ability.

Differently from the $17 \alpha$-monoesters of cortexolone, 9,11dehydrocortexolone-17 $\alpha$-butyrate (9) was found to show systemic activity in the rat after subcutaneous injection. ${ }^{\mathbf{1 2}}$

Compound 9 was also discovered to be a potent inhibitor of gonadotropin hypersecretion, thus mimicking the activity profile of cyproterone acetate (7), which blocks the androgen-

Table 2 Metabolism of 4 in rat plasma

\begin{tabular}{lll}
\hline $\begin{array}{l}\text { Incubation } \\
\text { time }\end{array}$ & $\begin{array}{l}\text { Cortexolone-17 } \alpha \text {-propionate } \\
(4)(\%)\end{array}$ & $\begin{array}{l}\text { Cortexolone } \\
(3)(\%)\end{array}$ \\
\hline 0 & 100 & 0 \\
$5 \mathrm{~min}$ & $95-90$ & $5-10$ \\
$15 \mathrm{~min}$ & $95-90$ & $5-10$ \\
$30 \mathrm{~min}$ & $90-80$ & $10-20$ \\
$1 \mathrm{~h}$ & $80-60$ & $20-40$ \\
$2 \mathrm{~h}$ & 50 & 50 \\
$4 \mathrm{~h}$ & $40-20$ & $60-80$ \\
$8 \mathrm{~h}$ & $10-0$ & $90-100$
\end{tabular}

receptor interaction and simultaneously reduces serum testosterone through its antigonadotropic action. ${ }^{\mathbf{1 3 , 1 4}}$ The presence of a double bond at position 9,11 of the cortexolone, modifying the spatial conformation of the steroids rings, could be responsible for the systemic and increased topical activity of $9 .{ }^{12}$

\section{Conformational properties}

The above observations prompted us to study the conformational properties of compound $\mathbf{4}$ and of the related compounds to establish and compare their preferred conformations. To this end, other known androgenic or antiandrogenic steroids were simultaneously analyzed including testosterone (1) and its most potent metabolite DHT (2) active in the skin, cortexolone (3) and its derivatives $\mathbf{8}$ and $\mathbf{9}$ and cyproterone acetate (7).

Conformational properties of compounds 1 and 2. An extensive exploration of the conformational space of compounds 1 and 2 was carried out through DFT calculations at the B3LYP/6-31G(d) level. Attention was focused on the tetracyclic system and on the possibility of inversion of the hexacyclic rings. Compound $\mathbf{1}$ prefers conformation $\mathbf{1 A}$ in which ring $\mathrm{A}$ assumed a half-chair geometry due to the presence of the double bond between $\mathrm{C} 4$ and C5. Conformation 1Ab differs from 1A (Fig. 3) only in the orientation of the hydroxyl group at $\mathrm{C} 17$ and it is less stable by $0.27 \mathrm{kcal} \mathrm{mol}^{-1}$. These two geometries account for more than $97 \%$ of the overall population (Table 6). The inversion of ring A (1B) resulted in a geometry less stable by about $2 \mathrm{kcal} \mathrm{mol}^{-1}$, whereas inversion of rings $\mathrm{B}$ and $\mathrm{C}$ gave two geometries (1C, 1D) less stable by 6.05 and 11.13 $\mathrm{kcal} \mathrm{mol}^{-1}$, respectively (Table 6). Concerning compound 2 , the preferred conformation A showed the expected chair geometry of the hexacyclic rings and a twisted geometry of ring D. The inversion of ring $\mathrm{A}$ is easier than the others, but the corresponding conformation (2B) is less stable by more than 3 $\mathrm{kcal} \mathrm{mol}^{-1}$, leaving $\mathbf{2 A}$ and the analogous $2 \mathbf{A b}$ conformation the only ones significantly populated; in fact, they account for more than $99 \%$ of the overall population. These two geometries differ only in the orientation of the hydroxyl group at C17 that has two accessible orientations with a small difference in energy $(0.31$ kcal mol ${ }^{-1}$ ). The preferred one is that with $\tau_{1} \approx 170^{\circ}(\mathbf{2 A})$ (Fig. 3 and Table 6).

Some short contacts characterize the conformational preferences of the rings of 2: $\mathrm{H}-2 \mathrm{ax} / \mathrm{CH}_{3}-10(2.81 \AA)$, and $\mathrm{H}-4 \mathrm{ax} / \mathrm{CH}_{3}$ $10(2.76 \AA)$ for the A ring; $\mathrm{H}-6 \mathrm{ax} / \mathrm{CH}_{3}-10(2.72 \AA), \mathrm{H}-8 \mathrm{ax} / \mathrm{CH}_{3}-10$ $(2.86 \AA)$ for the B-ring conformation; $\mathrm{H}-11 \mathrm{ax} / \mathrm{CH}_{3}-10(2.73 \AA)$, $\mathrm{H}-11 \mathrm{ax} / \mathrm{CH}_{3}-13$ (2.76 $\AA$ ), and $\mathrm{H}-8 \mathrm{ax} / \mathrm{CH}_{3}-13$ (2.78 $\AA$ ) for the C ring; $\mathrm{H}-15 \mathrm{ax} / \mathrm{CH}_{3}-13$ (2.90 $\mathrm{\AA}$ ) for ring $\mathrm{D}$.

Conformational properties of compounds 3, 4 and 7-9. The conformational space of compounds 3, 4, 7, 8 and 9 was analyzed at the same level as above. Analogously to 1, ring A presents, in all cases, an unsaturation between $\mathrm{C} 4$ and $\mathrm{C} 5$ that forces it to assume a half-chair geometry. In Table 6 the most representative conformations are reported. The preferred conformation of compounds 3, 4, 7, 8 and 9 (Fig. 4 and 5), located in the present study, corresponds, in the tetracyclic skeleton, to the geometry already determined at the same level of calculations for progesterone and a group of 13-ethylsteroids 
Table 3 Metabolism of 4 in human plasma

\begin{tabular}{llcr}
\hline Incubation time & Cortexolone-17 $\alpha$-propionate (4) (\%) & Cortexolone-21-propionate (5) (\%) & Cortexolone (3) (\%) \\
\hline 0 & 99.6 & 0.5 & 0.0 \\
$30 \mathrm{~min}$ & 93.2 & 6.5 & 0.4 \\
$1 \mathrm{~h}$ & 85.2 & 13.2 & 1.7 \\
$2 \mathrm{~h}$ & 67.2 & 25.3 & 7.5 \\
$4 \mathrm{~h}$ & 30.3 & 33.8 & 35.9 \\
$6 \mathrm{~h}$ & 11.3 & 23.8 & 64.9
\end{tabular}

and related estrogens modeled in previous papers. ${ }^{11}$ In fact, as can be seen from Table 6 , they show very close values of torsional angles $\left(\tau_{\mathrm{A}-\mathrm{C}}\right)$ and puckering coordinates.

The energy profiles for rotation around the $\mathrm{C} 17-\mathrm{C} 20$, and C17-O single bonds, defined by $\tau_{1}$ and $\tau_{2}$, were obtained and the preferred orientations determined. The C17-C20 bond showed a quite balanced distribution of its possible orientations, with the presence, for all compounds, of two significantly populated geometries that present $\tau_{1} \approx 160$, and $\tau_{1} \approx-10$, respectively. For 3 and 8 conformation $\mathbf{A b}$, with $\tau_{1} \approx-10$, is favoured by 0.63 and $1.29 \mathrm{kcal} \mathrm{mol}^{-1}$, respectively, whereas 4 and 9 prefer the other orientation by 0.46 and $0.25 \mathrm{kcal} \mathrm{mol}^{-1}$, respectively. Concerning the $\mathrm{C} 17-\mathrm{O}$ bond, in the case of $\mathbf{4}, \mathbf{8}$, and $\mathbf{9}$, a significant preference was observed for the orientation characterized by $\tau_{2} \approx-60^{\circ}$, with the other higher in energy by $4-6$ kcal $\mathrm{mol}^{-1}$, whereas in 3 the hydroxyl group bonded at $\mathrm{C} 17$ shows two orientations related to the value of $\tau_{1}$, being preferred $\tau_{2}=-45$ for $\tau_{1}=146$, and $\tau_{2}=-159$ for $\tau_{1}=-24$. In compound $\mathbf{8}$, the hydroxyl at $\mathrm{C} 21$, present in $\mathbf{3}, \mathbf{4}$, and $\mathbf{9}$, is esterified, with the generation of a second propionate group. Considering the oxoethyl propionate bonded at C17 the torsional angle $\tau_{3}$ describes the relative orientation of the two carbonyl groups of the chain. The second one is perpendicular to the first $\left(\tau_{3} \approx 90^{\circ}\right)$, whatever the orientation of this latter (see $\tau_{1}$ ).

A careful analysis of the conformational freedom of the tetracyclic skeleton allowed us to determine the facility of inversion of the three hexacyclic rings. The A ring inversion from the $1 \alpha, 2 \beta$-half-chair to the $1 \beta, 2 \alpha$-half-chair conformation $(\mathbf{3}, \mathbf{4}, \mathbf{8}, \mathbf{9 A}$ $\rightarrow 3,4,8,9 \mathrm{~B})$ is the easiest among all the possible ring inversions. In the case of compounds $\mathbf{3 , 4}$, and $\mathbf{8}$, the A ring inversion brings about a conformation less stable by about $2 \mathrm{kcal} \mathrm{mol}^{-1}$. For compound $\mathbf{9}$ the same inversion is easier, giving the conformation 9B with an energy value of $1.34 \mathrm{kcal} \mathrm{mol}^{-1}$. So the percentage contribution of the $1 \beta, 2 \alpha$-half-chair conformation to the overall population is double in the case of $\mathbf{9}$ with respect to the others, although the $1 \alpha, 2 \beta$-half-chair conformation remains widely preferred.

As regards B ring inversion, the obtained conformations $\mathbf{C}$, presenting a relative energy of about 4-6 $\mathrm{kcal} \mathrm{mol}^{-1}$, respectively, do not give any contribution to the overall population. The ring $\mathrm{C}$ inversion of $\mathbf{9}$ is not possible because of the presence of the double bond, whereas for $\mathbf{3 , 4}$ and $\mathbf{8}$ a conformation (D) is obtained that is higher in energy than the global minimum by more than $10 \mathrm{kcal} \mathrm{mol}^{-1}$.

In $3,4,8$ and 9 the preference of ring $\mathrm{A}$ for the $1 \alpha, 2 \beta$-halfchair conformation is characterized by the short contact $\mathrm{H}-2 \mathrm{ax} /$ $\mathrm{CH}_{3}-19(2.90 \AA)$. The contacts $\mathrm{H}-6 \mathrm{ax} / \mathrm{CH}_{3}-19$ (2.91 $⿱$ ) $)$, and $\mathrm{H}-8 \mathrm{ax} /$ $\mathrm{CH}_{3}-19(2.87 \AA)$ confirm the $\mathrm{B}$ ring conformation; contacts $\mathrm{H}-8 \mathrm{ax} / \mathrm{CH}_{3}-18$ (2.74 $\AA$ ), $\mathrm{H}-11 \mathrm{ax} / \mathrm{CH}_{3}-19$ (2.70 $\left.\mathrm{\AA}\right)$, and $\mathrm{H}-11 \mathrm{ax} / \mathrm{CH}_{3}$ $18(2.73 \AA)$ assure the $\mathrm{C}$ ring geometry, whereas contact $\mathrm{H}-15 \mathrm{ax} /$ $\mathrm{CH}_{3}-18$ (2.90 ̊) gives the D ring conformation.

Finally, the different orientations of $\tau_{1}$ could be verified through contacts $\mathrm{H}-21 \mathrm{~b} / \mathrm{H}-12 \mathrm{eq}(2.48,2.29,2.36 \AA$, respectively, for 3, 4, and 8) for conformation $\mathbf{A}$; $\mathrm{H}-21 \mathrm{a}, \mathrm{b} / \mathrm{CH}_{3}-18$ (2.63, 2.82, $2.90 \AA), \mathrm{H}-21 \mathrm{a} / \mathrm{H}-16(2.42,2.25,2.27 \AA)$, and $\mathrm{H}-21 \mathrm{~b} / \mathrm{H}-16$ (2.37, 2.43, $2.46 \AA$ ) for conformation $\mathbf{A b}$.

Analogously, conformation $\mathbf{A}$ of compound $\mathbf{9}$ presents the contacts: $\mathrm{H}-2 \mathrm{ax} / \mathrm{CH}_{3}-19(2.85 \AA)$ for ring A; H-6ax/ $\mathrm{CH}_{3}-19(2.94 \AA)$ for ring $\mathrm{B} ; \mathrm{H}-21 \mathrm{a} / \mathrm{H}-12 \mathrm{eq}(2.39 \AA)$ for $\tau_{1}=156$. The second orientation of $\tau_{1}$ could be verified through contacts: $\mathrm{H}-21 \mathrm{~b} / \mathrm{CH}_{3}$ -

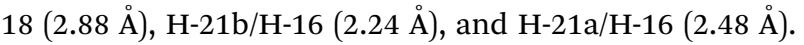

Table 4 Metabolism of 4 in rat skin homogenate

\begin{tabular}{llcc}
\hline Incubation time & Cortexolone-17 $\alpha$-propionate (4) (\%) & Cortexolone-21-propionate (5) (\%) & Cortexolone (3) (\%) \\
\hline 0 & 99 & 0.5 & 0 \\
$5 \mathrm{~min}$ & 99 & 0.5 & 0 \\
$15 \mathrm{~min}$ & 99 & 0.5 & 0 \\
$30 \mathrm{~min}$ & 98.5 & 0.5 & 0.5 \\
$1 \mathrm{~h}$ & 89.5 & 5 & 5 \\
$2 \mathrm{~h}$ & 69.5 & 15 & 15 \\
$4 \mathrm{~h}$ & 59.5 & 10 & 30 \\
$8 \mathrm{~h}$ & 49.5 & 10 & 40 \\
$16 \mathrm{~h}$ & 44.75 & 10 & 44.75 \\
$24 \mathrm{~h}$ & 44.75 & 10 & 44.75
\end{tabular}


Table 5 Local antiandrogenic activity of 4-related compounds 5, 8 and 9 in hamster flank organ test

Compound

Cortexolone-21-propionate (5)

Cortexolone-17 $\alpha, 21$-dipropionate (8)

9,11-Dehydrocortexolone- $17 \alpha$-butyrate $(9)^{12}$

Flank organ inhibition ${ }^{a}(\%)$

29

57

85

${ }^{a}$ Ability of the tested steroids $(400 \mu \mathrm{g})$ to inhibit the enlargement of the hamster's organ flank produced by the administration of $4 \mu \mathrm{g}$ of testosterone propionate.

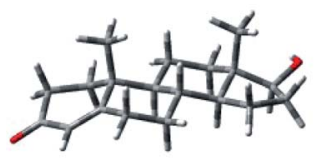

1A

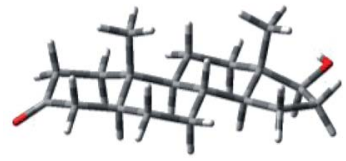

2A

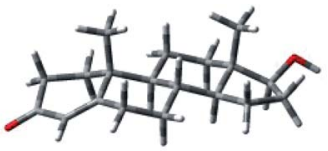

$1 \mathrm{Ab}$

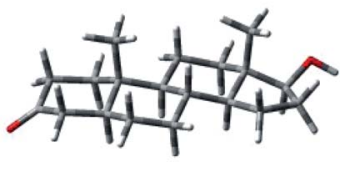

$2 \mathrm{Ab}$
Fig. 3 Three-dimensional plots of the most populated conformations of compounds 1 and 2 .

Compound 7 shows a rigid structure and the only degree of conformational freedom is the inversion of ring C. Rings A and B could not be inverted because of the presence of the cyclopropane ring and the double bond, respectively. Nevertheless, the $\mathrm{C}$ ring inversion gave conformations with a relative energy of about $13 \mathrm{kcal} \mathrm{mol}^{-1}$, giving no contribution to the overall population. So, only two geometries, $7 \mathbf{A}$ and $\mathbf{7 A b}$, are populated (Fig. 5). Conformation $\mathbf{A}$ of compound 7 presents the following contacts: $\mathrm{H}-11 \beta / \mathrm{CH}_{3}-18$ (2.24 $\left.\mathrm{A}\right), \mathrm{H}-11 \beta / \mathrm{CH}_{3}-19$ (2.29 ̊), H-8/ $\mathrm{CH}_{3}-19(2.76 \AA)$, and $\mathrm{H}-9 / \mathrm{CHa}-\mathrm{cPr}(2.66 \AA)$.

On the basis of crystallographic studies ${ }^{\mathbf{1 5}}$ performed on dihydrotestosterone (2) complexed with the ligand-binding domain of the wild-type androgen receptor, both the carbonyl oxygen atom bonded at C3 and the hydroxyl group at C17 of this molecule actively contribute to the stabilization of the obtained complex. The A ring conformation influences the orientation of the carbonyl group that deeply affects the binding of the entire molecule.

A docking study performed on $7,{ }^{16}$ into the homology model for the glucocorticoid receptor ligand binding domain, revealed that in the active site it assumes conformation $\mathbf{A}$.

The superimposition of the heavy atoms of the tetracyclic system of the preferred conformations of compounds $3, \mathbf{4}$ and 7-9 (Fig. 6) gave evidence that the presence of the hydroxyl group or the ester chain, bonded to $\mathrm{C} 21$ in compounds $3,4,8$ and $\mathbf{9}$, does not affect the orientation of the substituent at C17.

Compounds 3, 4, 8 and 9 show a very good overlay, also concerning the $\mathrm{O} 3$ atoms that are perfectly coincident, in spite of the presence in 9 of a double bond on ring C. Conversely, the overlay shows that in 7 the $\mathrm{O} 3$ atom is differently oriented and diverges with the distance $d(\mathrm{O}-\mathrm{O}) \approx 1.0 \AA$.

\section{NMR data}

Complete ${ }^{1} \mathrm{H}$ and ${ }^{13} \mathrm{C}$ NMR signal assignments (Tables 7-9) of the spectra of compounds 3, 4 and 7-9 were achieved using a combination of 1D and 2D (COSY, HSQC and NOESY) experiments recorded in $\mathrm{CDCl}_{3}$ at $298 \mathrm{~K}$. In general, starting from characteristic $\mathrm{H}-4, \mathrm{H}-7$ or $\mathrm{H}-11$ olefinic protons it was possible to assign the resonances of all the other protons of the studied steroids on the basis of their 2D spectra. First of all, H-8 was assigned through COSY correlations from $\mathrm{H}-4$ of compounds 3 , 4, 8 and 9 or from $\mathrm{H}-7$ of compound 7. Then, it was possible to discriminate between $\mathrm{H}-9$ and $\mathrm{H}-14$ (showing two very clear and distinctive HSQC cross-peaks accounting for $\mathrm{C}-\mathrm{H}$ protons) on the basis of $\mathrm{H}-9 / \mathrm{H}-11$ coupling, with $\mathrm{H}-11 \beta$ being assigned on the basis of its NOESY cross-peak with 19- $\mathrm{CH}_{3}$ (previously distinguished from $18-\mathrm{CH}_{3}$ that showed a NOESY correlation with the characteristic 21-protons). Also, $\mathrm{H}-1$, and consequently $\mathrm{H}-2$, resonances were assigned through the NOESY cross-peak of $\mathrm{H}-1 \beta$ and $19-\mathrm{CH}_{3}$. Finally, analysis of the $18-$ and $19-\mathrm{CH}_{3}$ NOESY cross-peak network was especially useful for the assignment of the $\alpha$ - or $\beta$-configuration of geminal protons (see Table 7) of all the studied compounds. Even if some protons in the ${ }^{1} \mathrm{H}$ NMR spectra resonated as complex multiplets (see Table 7 ), many signals were well resolved and their coupling could be measured. The obtained values are reported in Table 9 in comparison with the calculated constants of compounds 3,4 and 7-9. For each populated conformer the ${ }^{1} \mathrm{H}$ vicinal coupling constants were calculated with the electronegativity-modified Karplus relationship ${ }^{\mathbf{1 7}}$ and were weight-averaged on the basis of the population percentages. The experimental and the calculated values resulted in close agreement. The following nuclear Overhauser effect (nOe) contacts were observed in the NOESY spectra of the studied compounds. Compound 3: $\mathrm{CH}_{3}-19 / \mathrm{H}-1 \beta$, $\mathrm{H}-2 \beta, \mathrm{H}-6 \beta, \mathrm{H}-11 \beta$ and $\mathrm{H}-8 ; \mathrm{CH}_{3}-18 / \mathrm{H}-11 \beta, \mathrm{H}-12 \beta, \mathrm{H}-15 \beta, \mathrm{H}-16 \beta$, $\mathrm{H}-21 \mathrm{~b}$ and $\mathrm{H}-8$; $\mathrm{H}-21 \mathrm{a} / \mathrm{H}-12 \beta$ and $\mathrm{H}-16 \beta ; \mathrm{H}-21 \mathrm{~b} / \mathrm{H}-16 \beta$; and $\mathrm{H}-$ $7 \alpha / \mathrm{H}-9$ and $\mathrm{H}-14$. Compounds 4 and 8: $\mathrm{CH}_{3}-19 / \mathrm{H}-1 \beta, \mathrm{H}-2 \beta, \mathrm{H}-$ $6 \beta, \mathrm{H}-11 \beta$ and $\mathrm{H}-8 ; \mathrm{CH}_{3}-18 / \mathrm{H}-11 \beta, \mathrm{H}-12 \beta, \mathrm{H}-15 \beta, \mathrm{H}-16 \beta, \mathrm{H}-21 \mathrm{a}$ and $\mathrm{H}-8 ; \mathrm{H}-21 \mathrm{~b} / \mathrm{H}-12 \beta$ and $\mathrm{H}-16 \beta ; \mathrm{H}-21 \mathrm{a} / \mathrm{H}-16 \beta ; \mathrm{H}-8 / \mathrm{H}-15 \beta$; and $\mathrm{H}-7 \alpha / \mathrm{H}-9$ and $\mathrm{H}-14$. Compound 9: $\mathrm{CH}_{3}-19 / \mathrm{H}-1 \beta, \mathrm{H}-2 \beta, \mathrm{H}-6 \beta$, $\mathrm{H}-11$ (3.80 A calcd) and $\mathrm{H}-8 ; \mathrm{CH}_{3}-18 / \mathrm{H}-11$ (4.00 A calcd), $\mathrm{H}-12 \beta$, $\mathrm{H}-15 \beta, \mathrm{H}-16 \beta, \mathrm{H}-21 \mathrm{a}$ and $\mathrm{H}-8 ; \mathrm{H}-21 \mathrm{~b} / \mathrm{H}-12 \beta$ and $\mathrm{H}-16 \beta ; \mathrm{H}-21 \mathrm{a} / \mathrm{H}-$ $16 \beta ; \mathrm{H}-8 / \mathrm{H}-15 \beta$; and $\mathrm{H}-7 \alpha / \mathrm{H}-9$ and $\mathrm{H}-14$. Compound 7: $\mathrm{CH}_{3}-19$ / $\mathrm{H}-1, \mathrm{H}-11 \beta$ and $\mathrm{H}-8$; $\mathrm{CH}_{3}-18 / \mathrm{H}-11 \beta, \mathrm{H}-12 \beta, \mathrm{H}-15 \beta, \mathrm{H}-16 \beta, \mathrm{CH}_{3}-$ 21 and $\mathrm{H}-8 ; \mathrm{CH}_{3}-21 / \mathrm{H}-12 \beta$ and $\mathrm{H}-16 \beta ; \mathrm{H}-8 / \mathrm{H}-15 \beta$; and $\mathrm{H}-9$ / CHa-cPr.

These nOe data, such as the experimental values of the ${ }^{1} \mathrm{H}$ vicinal coupling constants, supported the calculated preferred 
Table 6 Geometrical features, relative energies, and equilibrium percentages of the selected conformations of compounds 1-4 and 7-9

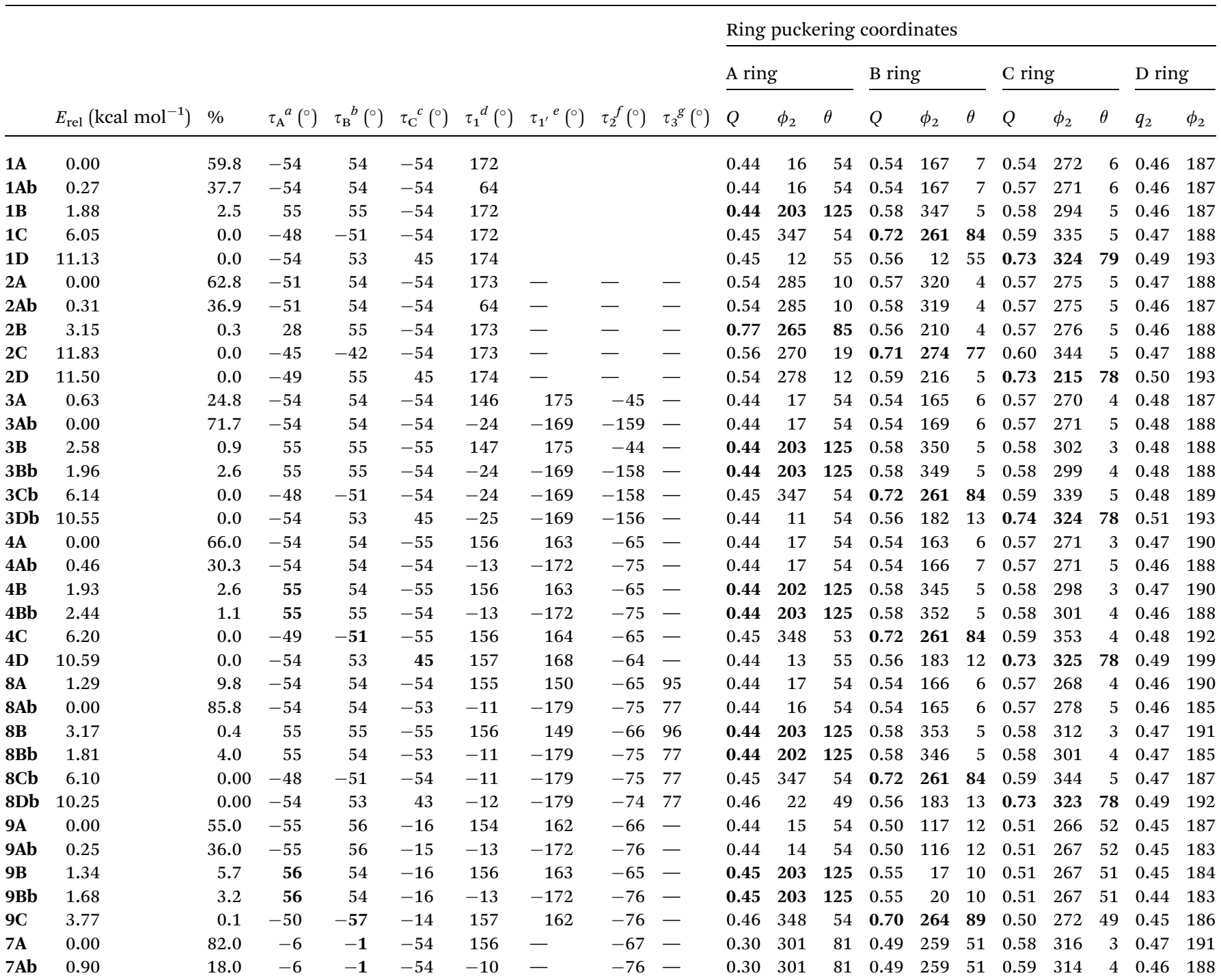

${ }^{a} \tau_{\mathrm{A}}: \mathrm{C} 10-\mathrm{C} 1-\mathrm{C} 2-\mathrm{C} 3 .^{b} \tau_{\mathrm{B}}: \mathrm{C} 5-\mathrm{C} 6-\mathrm{C} 7-\mathrm{C} 8 .^{c} \tau_{\mathrm{C}}: \mathrm{C} 9-\mathrm{C} 11-\mathrm{C} 12-\mathrm{C} 13 .^{d} \tau_{1}: \mathrm{C} 16-\mathrm{C} 17-\mathrm{O}-\mathrm{H}$ for 1 and 2, C16-C17-C20-C21 for 3, 4, 7-9. ${ }^{e} \tau_{1^{\prime}}:$ C17-C20$\mathrm{C} 21-\mathrm{O} .{ }^{f} \tau_{2}: \mathrm{C} 16-\mathrm{C} 17-\mathrm{O}-\mathrm{H}$ for $3, \mathrm{C} 16-\mathrm{C} 17-\mathrm{O}-\mathrm{C} 17^{\prime}$ for $4,7-9 .{ }^{g} \tau_{3}: \mathrm{C} 20-\mathrm{C} 21-\mathrm{O}-\mathrm{C} 22$.

conformations. In particular, almost all these contacts correspond to distances of $<3 \AA$ as measured on the computed (Fig. 4 and 5) most populated conformations of compounds 3, 4 and 7-9.

\section{Discussion}

Cortexolone-17 $\alpha$-propionate (4) is a steroid endowed with a strong local antiandrogenic activity but it is devoid of systemic antiandrogenic activity and it does not affect the hypersecretion of gonadotropins. Cortexolone-17 $\alpha$-propionate (4) does not inhibit the conversion of testosterone (1) to DHT (2) in reconstructed human epidermis, thus resulting in being devoid of activity on the $5 \alpha$-reductase. Nevertheless, compound 4 competes with the androgens at the androgen receptor level, and thus its strong antiandrogenic activity is attributable to this mechanism of action. As a consequence it is under investigation in the management of acne and alopecia.
In the present work a conformational comparison of 4 with testosterone (1), active testosterone metabolite DHT (2) and antiandrogen cyproterone acetate (7) (similar to $\mathbf{4}$ for the action mechanism direct on the androgen receptor) was carried out by means of theoretical calculations, supported by their complete high-field NMR characterization. In addition, the comparison was extended to the related compounds cortexolone (3), devoid of activity, cortexolone-17 $\alpha, 21$-dipropionate (8), less active, and $\Delta^{9}$-butyrate 9 , active both topically and systemically.

The conformational characterization showed that all compounds are similar (see Fig. 6), minor differences being observed: cyproterone acetate (7) has the 3-carbonyl group differently oriented and the presence of the 9,11-double bond hampers the $\mathrm{C}$ ring inversion in compound 9. However the 3-carbonyl group orientation ( 7 vs. 4 , Table 1) and the conformation of the $\mathrm{C}$ ring ( 9 vs. 4, Tables 1 and 5) do not influence the extent of the local antiandrogenic activity of the 


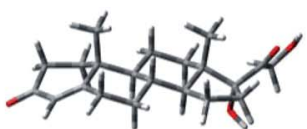

3A

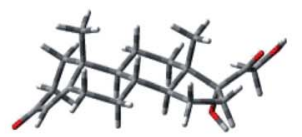

3B
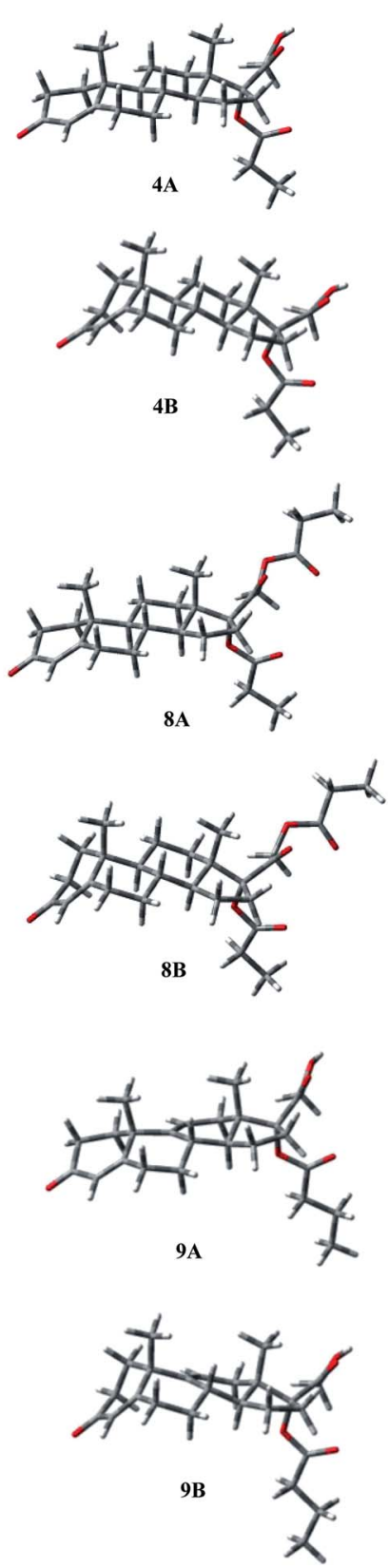

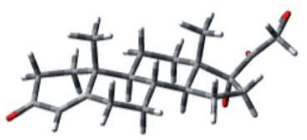

3Ab
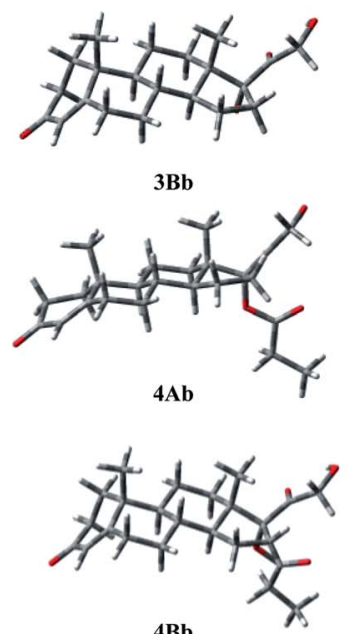

$4 B b$
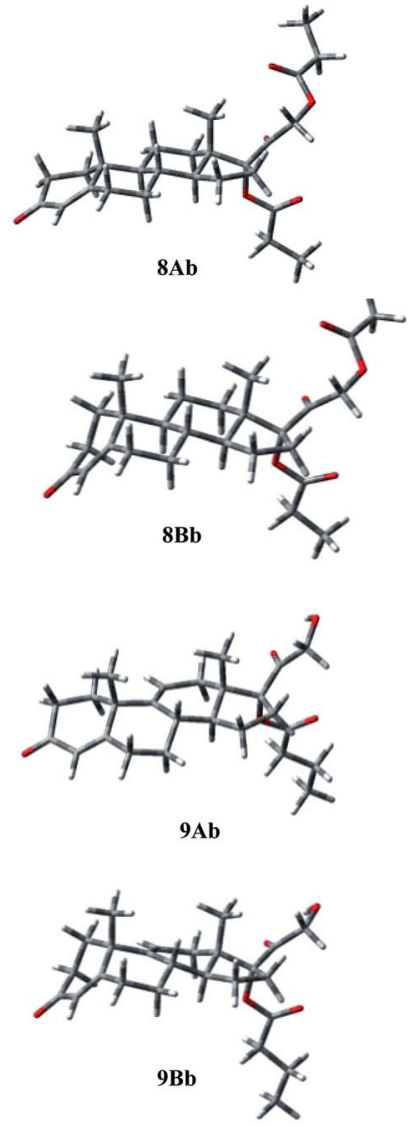

Fig. 4 Three-dimensional plots of the most significant conformations of compounds $3,4,8$ and 9 .

tested compounds. By contrast, the presence of the $17 \alpha$-ester group, which was always oriented in the same way from the conformational study, seems to be mandatory for a good
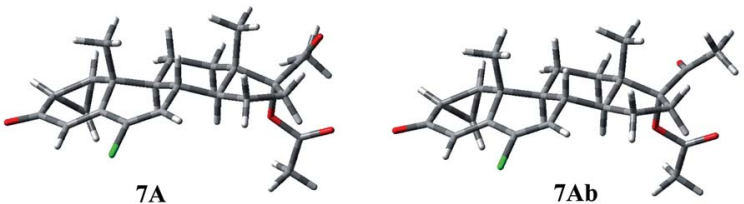

Fig. 5 Three-dimensional plots of the most significant conformations of compound 7 .

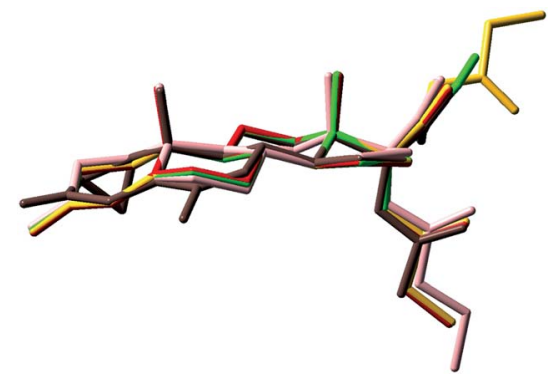

Fig. 6 Overlap of preferred conformations of compounds 3 (green shading), 4 (red shading), 8 (yellow shading), 9 (pink shading), and 7 (brown shading) obtained through rms fitting of the heavy atoms of the tetracyclic system.

inhibitory activity ( 3 vs. 4 , Table 1 ). In conclusion, the cortexolone series compounds 3-5 and 8, cyproterone acetate (7), and $\Delta^{9}-17 \alpha$-butyrate 9 share the same skeleton conformation but show different antiandrogenic activities due to the presence of an acyl chain linked to the $17 \alpha$-hydroxyl functionality. The same skeleton conformation of the examined compounds is consistent with the capability of each of them to interact, even with different outcomes, with the androgen receptors. Furthermore, the absence of systemic activity of $\mathbf{4}$ could be explained by its metabolic fate, i.e. the esterases-catalyzed hydrolysis of the acyl chain, after the rapid migration from the 17- to the 21-position.

\section{Experimental}

\section{Materials and methods}

All the cortexolone derivatives were from an internal source. Others steroids, Sephadex LH-20 and all reagents and solvents were purchased from Sigma Aldrich, Milan (Italy); Extrelut ${ }^{\circledR}$ NT columns were obtained from Merck.

\section{Biological tests}

Animals. Female Syrian golden hamsters and Wistar Han rats of both sexes (Charles River, Italy) were used in the experiments. The experiments were approved by the local Institutional Ethical Committee, and were conducted in agreement with the EEC Directive 86/609 and with the Italian Legislative Decree 116/27.01.1992 concerning the protection of animals used for experimental purpose or other scientific scope.

Hamster flank organ test. Female Syrian golden hamsters, 60-90 $\mathrm{g}$ body weight, were treated for 21 consecutive days with cortexolone-17 $\alpha$-propionate (4) and related compounds 5, 8, 9 
Table $7{ }^{1} \mathrm{H}$ NMR chemical shifts (ppm) of compounds 3, 4, and 7-9

\begin{tabular}{llllll}
\hline${ }^{1} \mathrm{H}$ & 3 & 4 & 7 & 8 & 9 \\
\hline 1 & & & 1.70 & & \\
$1 \alpha$ & 1.66 & 1.71 & - & 1.70 & $2.06-2.17$ \\
$1 \beta$ & 2.00 & 2.02 & - & 2.02 & $2.06-2.17$ \\
2 & & & 2.00 & & \\
$2 \alpha$ & 2.32 & 2.32 & - & 2.34 & $2.43-2.50$ \\
$2 \beta$ & 2.39 & 2.41 & - & 2.40 & $2.43-2.50$ \\
$\mathrm{CHa}(\mathrm{cPr})$ & - & - & 0.86 & - & - \\
$\mathrm{CHb}\left(\mathrm{cPr}^{2}\right.$ & - & - & 1.26 & - & - \\
4 & 5.70 & 5.72 & 6.16 & 5.72 & 5.74 \\
$6 \alpha$ & 2.26 & 2.27 & - & 2.27 & 2.35 \\
$6 \beta$ & 2.38 & 2.38 & - & 2.38 & 2.56 \\
7 & - & - & 6.20 & - & - \\
$7 \alpha$ & 1.08 & 1.10 & - & 1.08 & 1.16 \\
$7 \beta$ & 1.85 & 1.85 & - & 1.84 & 2.01 \\
8 & 1.59 & 1.60 & 2.31 & 1.62 & 2.22 \\
9 & 0.95 & 1.00 & 1.45 & 0.99 & - \\
11 & - & - & - & - & 5.52 \\
$11 \alpha$ & 1.62 & 1.65 & 1.94 & 1.65 & - \\
$11 \beta$ & 1.38 & 1.40 & 1.55 & 1.45 & - \\
$12 \alpha$ & 1.72 & 1.89 & 2.03 & 1.88 & 2.75 \\
$12 \beta$ & 1.40 & 1.54 & 1.61 & 1.74 & 1.76 \\
14 & 1.70 & 1.67 & 1.96 & 1.67 & 1.85 \\
$15 \alpha$ & 1.80 & 1.76 & 1.89 & 1.72 & 1.94 \\
$15 \beta$ & 1.37 & 1.35 & 1.44 & 1.34 & 1.45 \\
$16 \alpha$ & 1.57 & 1.85 & 1.82 & 1.84 & 1.97 \\
$16 \beta$ & 2.66 & 2.81 & 2.98 & 2.82 & 2.80 \\
$17\left(\mathrm{OCOCH}_{2}\right)$ & - & 2.34 & - & 2.35 & 2.28 \\
$17\left(\mathrm{OCOCH}_{2} \mathrm{CH}_{3}\right)$ & - & 1.12 & - & 1.13 & - \\
$17\left(\mathrm{OCOCH}_{2} \mathrm{CH}_{2}\right)$ & - & - & - & - & 1.62 \\
$17\left(\mathrm{OCOCH}_{2} \mathrm{CH}_{2} \mathrm{CH} H_{3}\right)$ & - & - & - & - & 0.93 \\
$17\left(\mathrm{OCOCH}_{3}\right)$ & - & - & 2.09 & - & - \\
$17 \mathrm{OH}^{2}$ & 2.45 & - & - & - & - \\
$18\left(\mathrm{CH}_{3}\right)$ & 0.68 & 0.66 & 0.71 & 0.74 & 0.61 \\
$19\left(\mathrm{CH}_{3}\right)$ & 1.16 & 1.17 & 1.21 & 1.16 & 1.32 \\
$21\left(\mathrm{CH}_{3}\right)$ & - & - & 2.04 & - & - \\
$21 \mathrm{a}$ & 4.28 & 4.21 & - & 4.59 & 4.24 \\
$21 \mathrm{~b}$ & 4.64 & 4.26 & - & 4.87 & 4.28 \\
$21\left(\mathrm{OCOCH}_{2}\right)$ & - & - & - & 2.45 & - \\
$21\left(\mathrm{OCOCH}_{2} \mathrm{CH}_{3}\right)$ & - & - & - & 1.15 & - \\
$21 \mathrm{OH}^{2}$ & & & & & 3.04 \\
& & & & &
\end{tabular}

applied directly onto the right flank organ at a daily dose ranging from 100 to $400 \mu \mathrm{g}$. The products were dissolved in $0.05 \mathrm{~mL}$ acetone solution containing $4 \mu \mathrm{g}$ of TP. Parent cortexolone (3), progesterone, cyproterone acetate (7) and finasteride (6) were also tested. Control groups of animals treated with TP alone have also been included. The antiandrogenic activity of the compounds was assessed by their ability to reduce the enlargement of the flank organs induced by TP alone.

Systemic antiandrogenic and glucocorticoid activity. Male castrated Wistar rats, 45-50 g body weight, were subcutaneously injected, for seven consecutive days, with cortexolone$17 \alpha$-propionate (4) or with 9,11-dehydrocortexolone-17 $\alpha$ butyrate (9) (0.2-1 and $5 \mathrm{mg})$, and with $40 \mu \mathrm{g}$ of TP. Parent cortexolone (3) was also tested at a daily dose of $5 \mathrm{mg}$. Control groups of untreated or treated animals with TP alone were also included. The antiandrogenic activity of $\mathbf{4}$ and $\mathbf{9}$ was evaluated by their ability to antagonize the androgenic effect
Table $8{ }^{13} \mathrm{C}$ NMR chemical shifts (ppm) of compounds 3, 4, and 7-9

\begin{tabular}{|c|c|c|c|c|c|}
\hline${ }^{13} \mathrm{C}$ & 3 & 4 & 7 & 8 & 9 \\
\hline 1 & 35.68 & 35.70 & 26.07 & 35.67 & 33.83 \\
\hline 2 & 33.87 & 33.91 & 25.22 & 33.92 & 34.22 \\
\hline $\mathrm{CH}_{2}(\mathrm{cPr})$ & - & - & 12.29 & - & - \\
\hline 3 & 199.58 & 199.26 & 197.94 & $\begin{array}{l}199.40 \\
(199.04)\end{array}$ & 199.05 \\
\hline 4 & 123.94 & 124.07 & 120.51 & 123.98 & 124.17 \\
\hline 5 & 170.93 & 170.33 & 155.22 & 170.61 & 169.01 \\
\hline 6 & 32.73 & 32.65 & 130.23 & 32.69 & 32.70 \\
\hline 7 & 31.98 & 31.91 & 136.51 & 31.91 & 32.13 \\
\hline 8 & 35.59 & 35.57 & 38.33 & 35.57 & 37.48 \\
\hline 9 & 53.28 & 53.16 & 47.70 & 53.14 & 144.20 \\
\hline 10 & 38.54 & 38.53 & 38.70 & 38.54 & 40.98 \\
\hline 11 & 20.52 & 20.50 & 20.78 & 20.57 & 118.25 \\
\hline 12 & 30.08 & 30.46 & 31.02 & 30.24 & 32.35 \\
\hline 13 & 48.57 & 47.72 & 47.24 & 47.79 & 46.28 \\
\hline 14 & 50.28 & 50.93 & 48.77 & 50.94 & 48.16 \\
\hline 15 & 23.70 & 23.89 & 23.23 & 23.77 & 24.65 \\
\hline 16 & 34.52 & 30.77 & 30.30 & 30.78 & 30.52 \\
\hline 17 & 89.00 & 93.77 & 96.18 & 94.86 & 93.33 \\
\hline 17 (OCO) & - & 174.05 & 170.55 & $\begin{array}{l}174.20 \\
(174.02)\end{array}$ & 173.24 \\
\hline $17\left(\mathrm{OCOCH}_{3}\right)$ & - & - & 21.17 & - & - \\
\hline $17\left(\mathrm{OCOCH}_{2}\right)$ & - & 27.77 & - & $\begin{array}{l}27.10 \\
(27.90)\end{array}$ & 36.24 \\
\hline $17\left(\mathrm{OCOCH}_{2} \mathrm{CH}_{3}\right)$ & - & 8.85 & - & $\begin{array}{l}8.97 \\
(8.90)\end{array}$ & - \\
\hline $17\left(\mathrm{OCOCH}_{2} \mathrm{CH}_{2}\right)$ & - & - & - & - & 18.31 \\
\hline $17\left(\mathrm{OCOCH}_{2} \mathrm{CH}_{2} \mathrm{CH}_{3}\right)$ & - & - & - & - & 13.57 \\
\hline 18 & 14.99 & 14.29 & 14.19 & 13.75 & 14.31 \\
\hline 19 & 17.36 & 17.39 & 22.83 & 17.35 & 26.20 \\
\hline 20 & 212.33 & 206.21 & 203.61 & $\begin{array}{l}199.40 \\
(199.04)\end{array}$ & 206.22 \\
\hline 21 & 67.42 & 66.93 & 26.43 & 66.88 & 66.91 \\
\hline 21 (OCO) & - & - & - & $\begin{array}{l}174.20 \\
(174.02)\end{array}$ & - \\
\hline $21\left(\mathrm{OCOCH}_{2}\right)$ & - & - & - & $\begin{array}{l}27.10 \\
(27.90)\end{array}$ & - \\
\hline $21\left(\mathrm{OCOCH}_{2} \mathrm{CH}_{3}\right)$ & - & - & - & $\begin{array}{l}8.97 \\
(8.90)\end{array}$ & - \\
\hline
\end{tabular}

induced by TP on the target androgenic organs: ventral prostate, seminal vesicles, and preputial glands. The weight reduction of adrenals and thymus was assumed as the glucocorticoid activity index.

Antigonadotropic activity. Wistar rats of both sexes, 50-60 g body weight, were employed. The males were castrated and, on the following day, they were surgically joined with intact females in latero-lateral parabiosis. In this model the castration induces a prompt increase of male gonadotropins which, in turn, reach the intact partner females and stimulate the ovarian growth. Starting on the day after parabiosis, each male was subcutaneously injected with cortexolone-17 $\alpha$-propionate (4) or with 9,11-dehydrocortexolone-17 $\alpha$-butyrate (9) at doses of 1 and $5 \mathrm{mg}$. Progesterone was assumed as the standard control and was administered, using the same procedure, at doses of 0.5 and $2 \mathrm{mg}$. The treatment lasted for eight consecutive days, after which the couples were autopsied. The ovaries were isolated and weighed. The inhibitory activity against gonadotropin hypersecretion, induced by castration in the 
Table $9{ }^{1} \mathrm{H}$ NMR coupling constants $(\mathrm{Hz})$ of compounds 3, 4, and 7-9

\begin{tabular}{|c|c|c|c|c|c|c|c|c|c|c|}
\hline$J$ & $\begin{array}{l}3 \\
\operatorname{Exp}\end{array}$ & $\begin{array}{l}3 \\
\text { Calc }\end{array}$ & $\begin{array}{l}\mathbf{4} \\
\text { Exp }\end{array}$ & $\begin{array}{l}\mathbf{4} \\
\text { Calc }\end{array}$ & $\begin{array}{l}7 \\
\operatorname{Exp}\end{array}$ & $\begin{array}{l}7 \\
\text { Calc }\end{array}$ & $\begin{array}{l}\mathbf{8} \\
\text { Exp }\end{array}$ & $\begin{array}{l}8 \\
\text { Calc }\end{array}$ & $\begin{array}{l}9 \\
\operatorname{Exp}\end{array}$ & $\begin{array}{l}9 \\
\text { Calc }\end{array}$ \\
\hline $1 \alpha, 1 \beta$ & 13.4 & & 13.4 & & - & & 13.4 & & n.d. & \\
\hline $1 \alpha, 2 \alpha$ & 4.5 & 4.0 & 5.0 & 3.9 & - & & n.d. & 3.9 & n.d. & 3.9 \\
\hline $1 \alpha, 2 \beta$ & n.d & 13.5 & n.d & 13.5 & - & & n.d. & 13.6 & n.d. & 13.6 \\
\hline $1 \beta, 2 \alpha$ & 3.2 & 2.9 & 3.3 & 2.9 & - & & 2.7 & 2.9 & n.d. & 2.9 \\
\hline $1 \beta, 2 \beta$ & 5.0 & 3.4 & 5.0 & 3.4 & - & & 4.8 & 3.4 & n.d. & 3.5 \\
\hline $2 \beta, 2 \alpha$ & 16.7 & & 16.7 & & - & & n.d. & & n.d. & \\
\hline 1,2 & - & & - & & 7.9 & 10.5 & - & & - & \\
\hline 1, $\mathrm{CHa}(\mathrm{cPr})$ & - & & - & & 6.4 & 9.5 & - & & - & \\
\hline 1,CHb (cPr) & - & & - & & 7.9 & 10.3 & - & & - & \\
\hline 2, $\mathrm{CHa}(\mathrm{cPr})$ & - & & - & & 4.5 & 8.2 & - & & - & \\
\hline 2, $\mathrm{CHb}(\mathrm{cPr})$ & - & & - & & 8.9 & 10.4 & - & & - & \\
\hline CHa,CHb(cPr) & - & & - & & 4.8 & & - & & - & \\
\hline $6 \alpha, 6 \beta$ & 14.6 & & 14.6 & & - & & 14.5 & & 14.4 & \\
\hline $6 \alpha, 7 \alpha$ & 4.3 & 3.7 & 4.2 & 3.7 & - & & 4.0 & 3.7 & 3.9 & 3.3 \\
\hline $6 \alpha, 7 \beta$ & 2.4 & 2.9 & 2.4 & 2.9 & - & & 2.4 & 2.9 & 2.6 & 3.1 \\
\hline $6 \beta, 4$ & n.d. & & n.d & & - & & n.d. & & 1.9 & \\
\hline $6 \beta, 7 \alpha$ & 12.0 & 13.2 & 11.5 & 13.3 & - & & 12.0 & 13.3 & 14.4 & 13.4 \\
\hline $6 \beta, 7 \beta$ & n.d. & 3.8 & 5.0 & 3.8 & - & & n.d. & 3.8 & 4.8 & 3.5 \\
\hline $7 \alpha, 7 \beta$ & 13.0 & & 13.7 & & - & & 14.0 & & 12.4 & \\
\hline $7 \alpha, 8$ & 12.0 & 12.3 & 12.5 & 12.3 & - & & 12.0 & 12.4 & 12.5 & 12.4 \\
\hline $7 \beta, 8$ & n.d. & 3.4 & 3.3 & 3.2 & - & & 3.3 & 3.2 & 4.7 & 3.2 \\
\hline 7,8 & - & & - & & 2.0 & 1.0 & - & & - & \\
\hline 8,9 & 10.8 & 12.1 & 11.0 & 12.3 & 9.8 & 12.9 & 10.8 & 12.9 & - & \\
\hline 8,14 & n.d. & 12.1 & 11.0 & 12.3 & 10.0 & & 10.8 & & 10.8 & \\
\hline $8,12 \alpha$ & - & & - & & - & & - & & 2.9 & \\
\hline $8,12 \beta$ & - & & - & & - & & - & & 2.0 & \\
\hline 11,8 & - & & - & & - & & - & & 2.0 & \\
\hline $11,12 \alpha$ & - & & - & & - & & - & & 2.9 & 2.0 \\
\hline $11,12 \beta$ & - & & - & & - & & - & & 5.9 & 6.4 \\
\hline $9,11 \alpha$ & 4.2 & 3.4 & 4.0 & & 3.0 & & 4.1 & & - & \\
\hline $9,11 \beta$ & 11.8 & 12.3 & 12.5 & & 12.8 & & 13.0 & & - & \\
\hline $11 \alpha, 12 \alpha$ & n.d. & 3.8 & 4.3 & 3.8 & n.d. & & 4.3 & 4.0 & - & \\
\hline $11 \alpha, 12 \beta$ & n.d. & 2.8 & 2.9 & 2.9 & 2.7 & & n.d. & 2.6 & - & \\
\hline $11 \beta, 12 \alpha$ & n.d. & 13.2 & 13.0 & 13.2 & 12.8 & & 13.2 & 13.1 & - & \\
\hline $11 \beta, 12 \beta$ & n.d. & 4.1 & 4.2 & 4.0 & 4.0 & & 4.2 & 4.4 & - & \\
\hline $11 \alpha, 11 \beta$ & n.d. & & 13.4 & & 12.8 & & 13.2 & & - & \\
\hline $12 \alpha, 12 \beta$ & n.d. & & 13.0 & & 12.6 & & 13.0 & & 17.0 & \\
\hline $14,15 \alpha$ & n.d. & 5.8 & 7.0 & 5.4 & n.d. & & n.d. & & 7.7 & 6.1 \\
\hline $14,15 \beta$ & n.d. & 11.6 & 11.8 & 11.8 & 11.0 & & 11.3 & & 11.0 & 11.3 \\
\hline $15 \alpha, 16 \alpha$ & 9.4 & 11.0 & 9.4 & 11.8 & 9.2 & & n.d. & 12.0 & 9.4 & 11.0 \\
\hline $15 \alpha, 16 \beta$ & 3.0 & 2.3 & 2.6 & 2.1 & 2.4 & & 2.5 & 2.6 & 3.0 & 2.7 \\
\hline $15 \alpha, 15 \beta$ & n.d. & & 11.8 & & 11.6 & & 11.3 & & 17.0 & \\
\hline $15 \beta, 16 \alpha$ & 6.2 & 5.4 & 6.5 & 5.7 & 6.0 & & 6.5 & 4.7 & 5.0 & 4.9 \\
\hline $15 \beta, 16 \beta$ & 11.5 & 12.0 & 11.8 & 11.8 & 10.2 & & 11.3 & 12.0 & 12.5 & 12.0 \\
\hline $16 \alpha, 16 \beta$ & 14.8 & & 16.0 & & 15.7 & & 15.7 & & 15.2 & \\
\hline $21 \mathrm{a}, 21 \mathrm{~b}$ & 19.8 & & 18.2 & & - & & 16.5 & & 18.3 & \\
\hline 21a,OH & 4.5 & & 4.9 & & - & & - & & 4.9 & \\
\hline $21 \mathrm{~b}, \mathrm{OH}$ & 4.5 & & 4.9 & & - & & - & & 4.8 & \\
\hline
\end{tabular}

males, was evaluated by the ability of $\mathbf{4}$ and $\mathbf{9}$ to antagonise the ovarian weight increase.

\section{Metabolism}

Metabolism in rat and human plasma. Samples of rat plasma were incubated at $37.8{ }^{\circ} \mathrm{C}$ with cortexolone-17 $\alpha$ propionate (4) $\left(0.4 \mathrm{mg} \mathrm{mL} \mathrm{m}^{-1}\right)$ for $8 \mathrm{~h}$ in the presence or absence of $50 \mu \mathrm{g}$ of enzymatic inhibitor dichlorvos. Determination of 4 , free cortexolone (3), and cortexolone-21propionate (5) were carried out at 5, 15, and $30 \mathrm{~min}$ and 1, 2, 4 , and $8 \mathrm{~h}$ incubation periods by HPLC. Samples of human plasma were incubated with cortexolone-17 $\alpha$-propionate (4) $\left(0.4 \mathrm{mg} \mathrm{mL}{ }^{-1}\right)$ at $37.8{ }^{\circ} \mathrm{C}$ for $6 \mathrm{~h}$. Determination of 4 , free cortexolone (3), and cortexolone-21-propionate (5) was performed at $30 \mathrm{~min}$ and $1,2,4$, and $6 \mathrm{~h}$ incubation periods by HPLC.

Metabolism in rat skin homogenate. Dorsal skin samples of male rats (Harlan Laboratories, Italy) were homogenised and incubated at $36.5{ }^{\circ} \mathrm{C}$ with cortexolone-17 $\alpha$-propionate (4) $\left(0.4 \mathrm{mg} \mathrm{mL}{ }^{-1}\right)$. Determination of $\mathbf{4}$, free cortexolone (3) and cortexolone-21-propionate (5) were done at $30 \mathrm{~min}$ and at 1, 4, 8, 16 , and $24 \mathrm{~h}$ incubation periods by HPLC. 


\section{Determination of 3, 4 and 5 by LC-MS and HPLC analyses}

Instruments. HPLC analyses were performed using a MerckHitachi L-6200. An LiChrospher 100 RP-18 (Merck) column $(244 \mathrm{~mm} \times 4 \mathrm{~mm}$ i.d., $5 \mu \mathrm{m})$ was employed; acetonitrile-water $(65 / 35 \mathrm{v} / \mathrm{v})$ was used at flow rate of $1 \mathrm{~mL} \mathrm{~min}^{-1}$, at room temperature. The detector wavelength was set at $240 \mathrm{~nm}$. Mass spectrometry analysis was carried out using an $\mathrm{LCQ}^{\mathrm{DECA}}$ ion trap mass analyser (TermoQuest, San Jose, USA) with an electrospray ionization ESI interface in negative ion mode. The HPLC apparatus comprised a Thermo Finningan Mat P 4000 series pump and vacuum degasser. The method was adapted from the method developed for HPLC-UV assay (same column, flow rate and mobile phase). Data were processed using Xcalibur software 1.1. The optimized parameters were as follows: source voltage $5.00 \mathrm{kV}$; sheath gas flow rate $50 \mathrm{~mL} \mathrm{~min}^{-1}$; capillary voltage $-15 \mathrm{~V}$; capillary temp. $250{ }^{\circ} \mathrm{C}$.

Preparation of samples. The samples obtained from incubations were loaded onto an Extrelut ${ }^{\circledR}$ NT column; the steroids were eluted using ethyl acetate $(3 \times 5 \mathrm{~mL})$. The combined organic extracts were evaporated under a stream of nitrogen at $50{ }^{\circ} \mathrm{C}$. The dried extracts were dissolved in cyclohexane-ethyl acetate $(7: 3,0.5 \mathrm{~mL})$ and purified by gel chromatography on a Sephadex LH-20 column using cyclohexane-ethyl acetate $(7: 3)$ as the eluant; the first eluted $15 \mathrm{~mL}$ were collected and taken to dryness under a stream of nitrogen.

LC-MS analysis. The samples were dissolved in acetonitrile $(1 \mathrm{~mL})$ and an amount $(15 \mu \mathrm{l})$ was analyzed by LC-MS. The observed peaks were identified, by comparison with standard samples, as cortexolone (3), cortexolone-17 $\alpha$-propionate (4) and cortexolone-21-propionate (5). The three standard solutions $\left(1 \mathrm{mg} \mathrm{mL}{ }^{-1}\right)$ were previously injected $(5 \mu \mathrm{l})$; the retention time and the observed $\mathrm{m} / \mathrm{z}$ values are reported in Table 10 .

In order to quantify the percentage of each compound the samples were analyzed by HPLC.

HPLC analysis. The quantitative analysis was performed by HPLC, using the same samples analyzed by LC-MS, the results being expressed as area\%: the three standard solutions and the samples of plasma and of skin homogenates were analyzed in duplicate.

Statistical analyses. The data collected in the animal studies have been statistically analyzed for significant differences according to Student's test. A $P$ value of $<0.05$ was considered statistically significant.

\section{Computational methods}

All calculations were carried out using the Gaussian03 ${ }^{18}$ program package. The conformational space of compounds 1-4

Table 10 Retention time and observed $\mathrm{m} / \mathrm{z}$ values of standard samples 3, 4 and 5

\begin{tabular}{llll}
\hline Std & $M$ & RT $(\mathrm{min})$ & $m / z$ \\
\hline $\mathbf{3}$ & 346.21 & $3.48-3.89$ & $345.0[\mathrm{M}-1], 691.3[2 \mathrm{M}-1]$ \\
$\mathbf{4}$ & 402.24 & $5.38-5.67$ & $803.1[2 \mathrm{M}-1]$ \\
$\mathbf{5}$ & 402.24 & $7.05-7.59$ & $803.2[2 \mathrm{M}-1]$
\end{tabular}

and 7-9 was explored through optimization of all the possible starting geometries which were optimized within the DFT approach at the B3LYP level with the 6-31G(d) basis set. All the degrees of conformational freedom were considered, in particular the possible existence of different conformations at the A, $\mathrm{B}$, and $\mathrm{C}$ hexacyclic rings as well as the orientation of the groups bonded at C17. Several conformations were located for each compound and the corresponding percentage contributions to the overall population were determined using the Boltzmann equation. The geometry of the rings A-C is described through two kinds of descriptors, i.e., a significant torsion angle for each ring, $\tau_{\mathrm{A}}, \tau_{\mathrm{B}}, \tau_{\mathrm{C}}$, and the ring-puckering coordinates determined according to Cremer and Pople. ${ }^{19}$ Vibrational frequencies were computed at the same level as above in order to verify that the optimized structures were minima. The ${ }^{1} \mathrm{H}$ vicinal coupling constants were calculated with the electronegativity-modified Karplus relationship ${ }^{\mathbf{1 7}}$ and were weight-averaged on the basis of the population percentages.

\section{NMR spectroscopy}

All NMR spectra were recorded at $298 \mathrm{~K}$ using a Bruker AVANCE500 spectrometer operating at 500.13 and $125.76 \mathrm{MHz}$ for ${ }^{1} \mathrm{H}$ and ${ }^{13} \mathrm{C}$, respectively, using a $5 \mathrm{~mm}$ single-pulsed field gradient ( $z$-PFG) broadband reverse probe. Chemical shifts are reported on the $\delta(\mathrm{ppm})$ scale and are relative to chloroform signals (7.24 for ${ }^{1} \mathrm{H}$ and $77.0 \mathrm{ppm}$, central line, for ${ }^{13} \mathrm{C}$ spectra respectively). Compounds 3, 4 and 7-9 (about $10 \mathrm{mg}$ ) were dissolved in $\mathrm{CDCl}_{3}$ (0.5 mL) under $\mathrm{N}_{2}$, and their assignments were given by a combination of 1D and 2D COSY, HSQC and NOESY experiments, using standard Bruker pulse programs. $z$-PFGs were used to obtain ${ }^{1} \mathrm{H}-{ }^{1} \mathrm{H}$ COSY and HSQC spectra. The pulse widths were $7.50 \mu \mathrm{s}\left(90^{\circ}\right)$ and $14.5 \mu \mathrm{s}\left(90^{\circ}\right)$ for ${ }^{1} \mathrm{H}$ and ${ }^{13} \mathrm{C}$ respectively. Typically, 32768 data points were collected for one-dimensional spectra. Spectral widths were $11.45 \mathrm{ppm}$ (5733 Hz) for ${ }^{1} \mathrm{H}$ NMR (digital resolution: $0.17 \mathrm{~Hz}$ per point) and $259.84 \mathrm{ppm}\left(32680 \mathrm{~Hz}\right.$ ) for ${ }^{13} \mathrm{C}$ NMR (digital resolution: $1.0 \mathrm{~Hz}$ per point). $2 \mathrm{D}$ experiments parameters were as follows. For ${ }^{1} \mathrm{H}-{ }^{1} \mathrm{H}$ correlations: relaxation delay $2.0 \mathrm{~s}, 1024 \times 1024$ data point matrices (512 experiments to 1024 zero filling in F1, 1024 in F2), 2 or 16 transients in each experiment for COSY and NOESY respectively, spectral width $6.0 \mathrm{ppm}(3004.8 \mathrm{~Hz})$. The NOESY spectra were generated with a mixing time of $1.0 \mathrm{~s}$ and acquired in the TPPI mode. There were no significant differences in the results obtained at different mixing times (0.5$1.5 \mathrm{~s}$ ). For ${ }^{13} \mathrm{C}-{ }^{1} \mathrm{H}$ correlations (HSQC): relaxation delay $2.5 \mathrm{~s}$, $1024 \times 1024$ data point matrices (512 experiments to 1024 zero filling in F1, 1024 in F2), 2 transients in each experiment, spectral width $6.0 \mathrm{ppm}(3004.8 \mathrm{~Hz})$ in the proton domain and $180.0 \mathrm{ppm}(22638.6 \mathrm{~Hz})$ in the carbon domain. All 2D spectra were processed using the Bruker software package.

\section{Acknowledgements}

This work was financially supported by Università di Milano, by Università di Pavia and by Cosmo Research \& Development 
S.p.A. The authors warmly thank Professor Lucio Toma for very helpful discussion.

\section{Notes and references}

$1 \mathrm{~W}$. Chen, D. Thiboutout and C. C. Zouboulis, J. Invest. Dermatol., 2002, 119, 992-1007.

2 C. R. Darley, J. D. Kirby, G. M. Besser, D. D. Munro, C. R. Edwards and L. H. Rees, Br. J. Dermatol., 1982, 106, 517-522.

3 J. H. Barth, Drugs, 1988, 35, 83-91.

4 G. Sansone and R. M. Reisner, J. Invest. Dermatol., 1971, 56, 366-372.

5 V. H. Price, Arch. Dermatol., 1975, 111, 1496-1502.

6 C. Chen, X. Li, S. M. Singh and F. Labrie, J. Invest. Dermatol., 1998, 111, 273-278.

7 J. R. Brooks, R. L. Primia, C. Berman, D. A. Krupa, G. F. Reynolds and G. H. Rasmusson, Steroids, 1991, 56, 428-433.

8 G. Celasco, L. Moro, R. Bozzella, P. Ferraboschi, L. Bartorelli, C. Quattrocchi and F. Nicoletti, Arzneim.-Forsch./Drug Res., 2004, 54, 881-886.

9 E. M. Glenn, S. L. Richardson and B. J. Bowman, Metabolism, 1959, 8, 265-285.

10 W. Voigt and S. L. Hsia, Endocrinology, 1973, 92, 1216-1222. 11 (a) D. Colombo, P. Ferraboschi, P. Prestileo and L. Toma, J. Steroid Biochem. Mol. Biol., 2006, 98, 56-62; (b) D. Colombo, P. Ferraboschi, L. Legnani, P. Prestileo and L. Toma, J. Steroid Biochem. Mol. Biol., 2007, 103, 163-169.

12 G. Celasco, L. Moro, R. Bozzella, P. Ferraboschi, L. Bartorelli, R. Di Marco, C. Quattrocchi and F. Nicoletti, Arzneim. Forsch., 2005, 55, 581-587.

13 H. J. de Voogt, Prostate, 1992, 21(S4), 91-95.

14 P. Reid, P. Kantoff and W. Oh, Invest. New Drugs, 1999, 17, 271-284.
15 J. S. Sack, K. F. Kish, C. Wang, R. M. Attar, S. E. Kiefer, Y. An, G. Y. Wu, J. E. Scheffler, M. E. Salvati, S. R. Krystek Jr, R. Weinmann and H. M. Einspahr, Proc. Natl. Acad. Sci. U. S. A., 2001, 98, 4904-4909.

16 C. Honer, K. Nam, C. Fink, P. Marshall, G. Ksander, R. E. Chatelain, W. Cornell, R. Steele, R. Schweitzer and C. Schumacher, Mol. Pharmacol., 2003, 63, 1012-1020.

17 C. A. G. Haasnoot, F. A. A. M. de Leeuw and C. Altona, Tetrahedron, 1980, 36, 2783-2792.

18 M. J. Frisch, G. W. Trucks, H. B. Schlegel, G. E. Scuseria, M. A. Robb, J. R. Cheeseman, J. A. Montgomery Jr, T. Vreven, K. N. Kudin, J. C. Burant, J. M. Millam, S. S. Iyengar, J. Tomasi, V. Barone, B. Mennucci, M. Cossi, G. Scalmani, N. Rega, G. A. Petersson, H. Nakatsuji, M. Hada, M. Ehara, K. Toyota, R. Fukuda, J. Hasegawa, M. Ishida, T. Nakajima, Y. Honda, O. Kitao, H. Nakai, M. Klene, X. Li, J. E. Knox, H. P. Hratchian, J. B. Cross, C. Adamo, J. Jaramillo, R. Gomperts, R. E. Stratmann, O. Yazyev, A. J. Austin, R. Cammi, C. Pomelli, J. W. Ochterski, P. Y. Ayala, K. Morokuma, G. A. Voth, P. Salvador, J. J. Dannenberg, V. G. Zakrzewski, S. Dapprich, A. D. Daniels, M. C. Strain, O. Farkas, D. K. Malick, A. D. Rabuck, K. Raghavachari, J. B. Foresman, J. V. Ortiz, Q. Cui, A. G. Baboul, S. Clifford, J. Cioslowski, B. B. Stefanov, G. Liu, A. Liashenko, P. Piskorz, I. Komaromi, R. L. Martin, D. J. Fox, T. Keith, M. A. Al-Laham, C. Y. Peng, A. Nanayakkara, M. Challacombe, P. M. W. Gill, B. Johnson, W. Chen, M. W. Wong, C. Gonzalez and J. A. Pople, Gaussian 03, Revision B.04, Gaussian Inc., Pittsburgh PA, 2003.

19 D. Cremer and J. A. Pople, J. Am. Chem. Soc., 1975, 97, 13541358. 